\title{
PRELIMINARY COMMUNICATION
}

\section{INVESTIGATIONS ON ORGANOGERMANIUM COMPOUNDS \\ $\mathrm{X}^{\star}$. CATENATED ORGANOGERMANIUM COMPOUNDS. EVIDENCE FOR DIVALENT ORGANOGERMANIUM SPECIES}

\author{
E.J. BULTEN and J.G. NOLTES \\ Institute for Organic Chemistry TNO, Utrecht (The Netherlands) \\ (Received November 20th, 1968; in revised form December 2nd, 1968)
}

Investigations into linear alkylpolygermanes containing more than one $\mathrm{Ge}-\mathrm{Ge}$ bond have been hampered by lack of suitable preparative routes. The development of satisfactory methods for the preparation of trialkylgermyl alkali metal derivatives ${ }^{1-3}$ and of alkylhalodi- and -trigermanes ${ }^{4,5}$ allows the planned synthesis of linear alkylpolygermaries. Several such compounds have now been prepared (see Table 1) as follows:

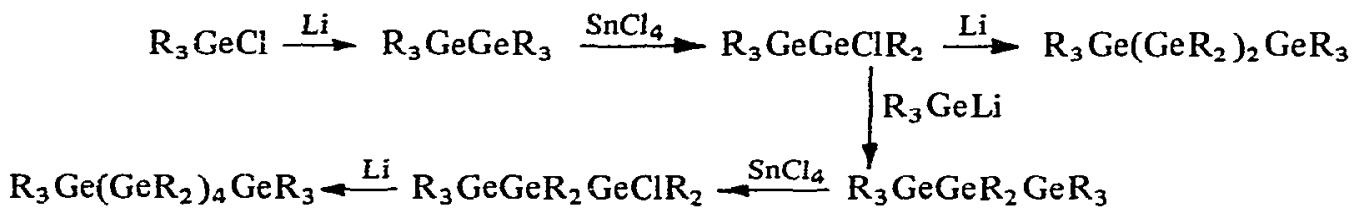

In the Wurtz-type couplings an excess of organogermanium halide must be used in order to minimize Ge-Ge bond cleavage, which leads to a mixture of polygermanes. For example reaction of an excess of $\mathrm{Et}_{3} \mathrm{GeGeClEt}_{2}$ with lithium in xylene yields $E t_{3} \mathrm{Ge}\left(\mathrm{GeEt}_{2}\right)_{2} \mathrm{GeEt}_{3}$ as the main product. When the same reaction is performed with an excess of alkali metal in HMPA a mixture of polygermanes is formed. From such a mixture a compound was isolated which in an earlier communication ${ }^{3}$ was considered to be $\mathrm{Et}_{3} \mathrm{Ge}\left(\mathrm{GeEt}_{2}\right)_{2} \mathrm{GeEt}_{3}$. However, the analytical data, UV absorption spectrum and refractive index (Table 1) of the latter product are in better agreement with linear $\mathrm{Et}_{12} \mathrm{Ge}_{5}$. In addition to this compound a considerable amount of $\mathrm{Et}_{B} \mathrm{Ge}_{3}$ was isolated, which points to a metal-metal bond cleavage by the excess of lithium applied or by an intermediately formed germyl-lithium compound ${ }^{3,6}$.

The perethylpolygermanes display a characteristic UV absorption. The absorption maximum shifts to longer wavelength with increasing chain length (Table 1). Similar observations have been reported for peralkylpolysilanes ${ }^{7}$ and - stannanes $^{8,9}$. The perethylpolygermanes are stable in air and have considerable thermal stability, e.g. linear $\mathrm{Et}_{14} \mathrm{Ge}_{6}$ was recovered in better than $80 \%$ yield after heating for $8 \mathrm{~h}$ at $250^{\circ}$ (under $\mathrm{N}_{2}$ ).

\footnotetext{
`For Part IX see ref. 5.
} 
TABLE 1

PHYSICAL DATA FOR SOME PERETHYLPOLYGERMANES $a$

\begin{tabular}{lllc}
\hline Compound & $\begin{array}{l}\text { B.p. } \\
(\mathrm{C} C / \mathrm{mm})\end{array}$ & $n_{\mathrm{D}}^{20}$ & $\begin{array}{l}\lambda_{\max } \\
(\mathrm{nm})\end{array}$ \\
\hline $\mathrm{Et}_{3} \mathrm{GeGeEt}_{3}$ & $130-132 / 16$ & 1.4985 & $\sim 202$ \\
$\mathrm{Et}_{3} \mathrm{GeGeEt} \mathrm{GeEt}_{3} b$ & $127-128 / 0.3$ & 1.5350 & 217.5 \\
$\mathrm{Et}_{3} \mathrm{Ge}\left(\mathrm{GeEt}_{2}\right)_{2} \mathrm{GeEt}_{3} c$ & $-d$ & 1.5561 & 233.5 \\
$\mathrm{Et}_{3} \mathrm{Ge}\left(\mathrm{GeEt}_{2}\right)_{3} \mathrm{GeEt}_{3} c$ & $155-160 / 5 \cdot 10^{-4}$ & 1.5748 & 248 \\
$\mathrm{Et}_{3} \mathrm{Ge}\left(\mathrm{GeEt}_{2}\right)_{4} \mathrm{GeEt}_{3}$ & $-d$ & 1.5912 & 258 \\
\hline
\end{tabular}

aSatisfactory analyses have been obtained for all compounds reported. $b$ Ref. 3 . cSee text. $d$ Purified by column chromatography $\left(\mathrm{Al}_{2} \mathrm{O}_{3}\right)$.

Introduction of functional groups bound to germanium decreases the thermal stability. As reported previously $\mathrm{Et}_{2} \mathrm{ClGeGeClEt}_{2}$ decomposes above $200^{\circ}$ to give $\mathrm{Et}_{2} \mathrm{GeCl}_{2}$ and a catenated germanium species ${ }^{4}$. Using gas chromatography it has now been found that $\mathrm{Et}_{2} \mathrm{ClGeGeClEt}_{2}$ disproportionates fairly rapidly at $230-250^{\circ}$ to give predominantly $\mathrm{Et}_{2} \mathrm{GeCl}_{2}$ and $\mathrm{Et}_{2} \mathrm{ClGeGeEt}_{2} \mathrm{GeClEt}_{2} \star$. Under the same conditions $\mathrm{Et}_{3} \mathrm{GeGeClEt}_{2}$ disproportionates according to:

$$
\mathrm{Et}_{3} \mathrm{GeGeClEt}_{2} \rightarrow \mathrm{Et}_{3} \mathrm{GeCl}+\mathrm{Et}_{3} \mathrm{Ge}\left(\mathrm{GeEt}_{2}\right)_{n} \mathrm{GeClEt}_{2}
$$

$$
\text { (III, } n=1 ; \text { IV }, n=2 \text { ) }
$$

The formation of tetragermane, presumably IV, was observed only after conversion of about $50 \%$ of the starting material into monogermane (I) and trigermane (III). A similar disproportionation has recently been reported for $\mathrm{Me}_{3} \mathrm{SiSi}(\mathrm{CN}) \mathrm{Me}_{2}{ }^{10}$ and $\mathrm{Me}_{6-n} \mathrm{Si}_{2}(\mathrm{OMe})_{n}{ }^{11}$.

Kinetic experiments revealed that the decomposition of $\mathrm{Et}_{3} \mathrm{GeGeClEt}_{2}$ is very nearly independent of concentration, which demonstrates that the reaction is predominantly unimolecular ( $c f$. ref. 11). These results point to a mechanism involving the formation and subsequent insertion of a divalent germanium species:

$$
\begin{aligned}
& \mathrm{Et}_{3} \mathrm{GeGeClEt}_{2} \rightarrow \mathrm{Et}_{3} \mathrm{GeCl}+\mathrm{Et}_{2} \mathrm{Ge}: \\
& \mathrm{Et}_{2} \mathrm{Ge}:+\mathrm{Et}_{3} \mathrm{GeGeClEt}_{2} \rightarrow \mathrm{Et}_{3} \mathrm{GeGeEt}_{2} \mathrm{GeClEt}_{2}
\end{aligned}
$$

The first order kinetics demonstrate that the formation of $\mathrm{Et}_{2} \mathrm{Ge}$ : is the rate-determining step.

The formation of $\mathrm{Et}_{3} \mathrm{GcCl}$ as the sole monogermane on thermolysis of $\mathrm{Et}_{3} \mathrm{GeGeClMe}_{2}$ indicates that a chlorine shift takes place, not an alkyl shift.

Insertion of $\mathrm{Et}_{2} \mathrm{Ge}$ into the $\mathrm{Ge}-\mathrm{Cl}$ bond seems highly plausible in view of the following results. Thermolysis of a $1: 1$ mixture of $\mathrm{Et}_{3} \mathrm{GeGeClEt}_{2}$ and $\mathrm{Me}_{3} \mathrm{GeCl}$ gives $\mathrm{Me}_{3} \mathrm{GeGeClEt}_{2}$ औ, in addition to $\mathrm{Et}_{3} \mathrm{GeCl}$ and $\mathrm{Et}_{3} \mathrm{GeGeEt}_{2} \mathrm{GeClEt}_{2}$. A small amount of another trigermane, presumably $\mathrm{Me}_{3} \mathrm{GeGeEt}_{2} \mathrm{GeClEt}_{2}$ is also formed.

\footnotetext{
tIdentified as $\mathrm{Et}_{8} \mathrm{Ge}_{3}$ after treatment with EtMgBr.

$\star \star \star_{\text {Identified as }} \mathrm{Me}_{3} \mathrm{GeGeEt}_{3}$ after ethylation ${ }^{1}$.
} 


$$
\mathrm{Me}_{3} \mathrm{GeCl} \stackrel{\mathrm{Et}_{2} \mathrm{Ge}:}{\longrightarrow} \mathrm{Me}_{3} \mathrm{GeGeClEt}_{2} \stackrel{\mathrm{Et}_{2} \mathrm{Ge}:}{\longrightarrow} \mathrm{Me}_{3} \mathrm{GeGeEt}_{2} \mathrm{GeClEt}_{2}
$$

Thermolysis of a 1:1 mixture of $\mathrm{Et}_{3} \mathrm{GeGeClEt}_{2}$ and $\mathrm{Et}_{6} \mathrm{Ge}_{2}$ gives only $\mathrm{Et}_{3} \mathrm{GeCl}$ and $\mathrm{Et}_{3} \mathrm{GeGeEt}_{2} \mathrm{GeClEt}_{2}$, with no trace of $\mathrm{Et}_{8} \mathrm{Ge}_{3}$.

So far attempts to trap $\mathrm{Et}_{2} \mathrm{Ge}$ : with carbon-carbon unsaturated systems (e.g. tolane) have been unsuccessful, insertion into the $\mathrm{Ge}-\mathrm{Cl}$ bond taking place instead.

Detailed information will be given at a later date ${ }^{12}$.

\section{ACKNOWLEDGEMENTS}

Financial support by the Germanium Research Committee is. gratefully acknowledged. The authors are much indebted to Professor G.J.M. van der Kerk for his stimulating interest, to Dr. W. Drenth for valuable suggestions and to Mr. K.P. Ligtvoet for able experimental assistance.

\section{REFERENCES}

1 E.J. Bulten and J.G. Noltes, Tetrahedron Letters, (1966) 4389.

2 N.S. Vyazankin, E.N. Gladyshev, G.A. Razuvaev and S.P. Komeva, Zh. Obshch. Khim., 36 (1966) 952.

3 E.J. Bulten and J.G. Noltes, Tetrahedron Letters, (1967) 1443.

4 E.J. Bulten and J.G. Noltes, ibid. (1966) 3471.

5 E.J. Bulter and J.G. Noltes, J. Organometal. Chem., 15 (1968) P18.

6 E.J. Bulten and J.G. Noltes, J. Organometal. Chem., 11 (1968) P19.

7 H. Gilman, W.H. Atwell and G.L. Schwebke, J. Organometal. Chem., 2 (1964) 369.

8 H.M.J.C. Creemers, $P h$. D. Thesis, State University of Utrecht, 1967.

9 H.M.J.C. Creemers and J.G. Noltes, J. Organometal. Chem., 7 (1967) 237.

10 J.V. Urenowitch and A.G. MacDiarmid, J. Amer. Chem. Soc., 85 (1963) 3372,

11 W.H. Atwell and D.R. Weyenberg, J. Amer. Chem. Soc., 90 (1968) 3438,

12 E.J. Bulten, $P h$. D. Thesis, State University of Utrecht, to be published.

J. Organometal. Chem., 16 (1969) P8-P10 